\title{
Madeleine et Francis Ambrière, Talma ou l'Histoire au Théâtre
}

Lise Sabourin

\section{(2) OpenEdition}

12 Journals

\section{Édition électronique}

URL : http://journals.openedition.org/studifrancesi/8290

DOI : 10.4000/studifrancesi.8290

ISSN : 2421-5856

Éditeur

Rosenberg \& Sellier

\section{Édition imprimée}

Date de publication : 1 mai 2009

Pagination : 187-188

ISSN : 0039-2944

\section{Référence électronique}

Lise Sabourin, « Madeleine et Francis Ambrière, Talma ou l'Histoire au Théâtre », Studi Francesi [En ligne], 157 (LIII | I) | 2009, mis en ligne le 30 novembre 2015, consulté le 09 janvier 2021. URL : http:// journals.openedition.org/studifrancesi/8290; DOI : https://doi.org/10.4000/studifrancesi.8290

Ce document a été généré automatiquement le 9 janvier 2021.

\section{(c) $(1) \&$}

Studi Francesi è distribuita con Licenza Creative Commons Attribuzione - Non commerciale - Non opere derivate 4.0 Internazionale. 


\title{
Madeleine et Francis Ambrière, Talma ou l'Histoire au Théâtre
}

\author{
Lise Sabourin
}

\section{RÉFÉRENCE}

MADELEINE et FRANCIS AMBRIÈRE, Talma ou l'Histoire au Théâtre, Paris, Éditions de Fallois, 2008, pp. 893.

1 Madeleine Ambrière publie aujourd'hui l'ouvrage qu'elle a rédigé sur les notes prises en compagnie de son mari, le regretté lauréat Goncourt des Grandes Vacances et l'auteur de deux précédentes sommes sur l'histoire de la sensibilité et de la société française du $\mathrm{XIX}^{\mathrm{e}}$ siècle, à travers des figures emblématiques du théâtre: Le Siècle des Valmore (Seuil, 1987) et Mademoiselle Mars et Marie Dorval au théâtre et dans la vie (Seuil, 1992). La célébrité de Talma a été tellement liée au pouvoir impérial que la postérité méconnaît l'avant, surtout, comme, un peu, l'après Napoléon dans sa carrière. L'acteur lui-même était conscient de la fragilité mémorielle et du caractère évolutif de l'appréciation historique portée sur sa fonction. Aussi cette enquête menée avec minutie dans les archives, bibliothèques et fonds privés, assortie d'une bibliographie, d'une chronologie fort précise et d'un index nominum, s'applique-t-elle à embrasser toute sa vie, dans ses dimensions personnelles comme publiques.

Madeleine et Francis Ambrière ont d'abord sondé les arcanes de son éducation, partagée entre des parents désunis mais soucieux d'assurer à leurs enfants un avenir meilleur: ainsi, dentiste par devoir, Talma pratique-t-il d'abord par pur plaisir la déclamation que lui enseigne le comédien Molé. Après ses débuts à la ComédieFrançaise en 1786, le jeune premier se lie avec Julie, danseuse à l'Opéra, connue par les dîners choisis qu'elle donnait en compagnie de son amant, le vicomte de Ségur. Leur mariage se révélera cependant fort malheureux pour cette jeune épistolière d'esprit, qui inspire d'abord quelques comédies à l'ambitieux, confiné dans des rôles secondaires, jusqu'à son interprétation du Charles IX de Chénier en 1789. Devenu alors 
«acteur d'un peuple en révolution», Talma partage les mutations de la troupe du Théâtre-Français, tant par ses scissions au fil des affectations et constructions de salles qu'entre comédiens, véritable «famille d'Atrides» (selon l'expression de Béatrice Dussane) qui verra naître le talent de Mlle George au prix d'une cabale. Ballotté par la Terreur, soupçonné pour ses relations avec les Girondins, il a vu arriver avec soulagement le Directoire, puis le Consulat. Après un divorce peu élégant, laissant Julie révoltée et démunie, Talma épouse Caroline Vanhove et incarne les rôles shakespeariens adaptés par Ducis. De tournées, lucratives pour cet homme toujours endetté, parfois tenté par un exil doré, en rôles tragiques des grandes pièces classiques (Cinna notamment), mais aussi de dramaturges contemporains (Les Templiers de Raynouard, Manlius de La Fosse), l'acteur se hisse au plus près d'un Empereur protecteur qui sait utiliser son talent lors de fastueuses représentations à Saint-Cloud, Compiègne, Fontainebleau et même à Erfurt, lors de la rencontre avec le Tsar. Malgré les dures critiques de Geffroy (et la louange fort compromettante de Mme de Staël qui veut l'inviter à Coppet), malgré aussi une maladie des nerfs qui l'éloigne de la scène en 1809-1810, son étoile continue de monter au point de connaître son apogée sous la Restauration. Avec souplesse et zèle, flanqué d'une autre Caroline (Bazire), nouvelle compagne qui lui vaut un procès en séparation, mais d'autant plus forte qu'attentive à ses faux pas, il se fait habile courtisan des Bourbons, tout en négociant avec certaine perversité son départ à la retraite de la salle Richelieu au profit de théâtres provinviaux plus laudateurs et fructueux. Alors que «le menace le naufrage de la vieillesse, du crépuscule d'un dieu, bientôt émergera le sublime Talma» (p. 553) qui incarne encore les protagonistes du répertoire classique, l'Abufar de Ducis et, s'éloignant des chemins de traverse parisiens, le Sylla de Jouy à Bruxelles en 1822, enfin l'Agamemnon de Soumet à la Comédie-Française. L'«adorable» tragédien de L'École des vieillards en 1823 est moins convaincu qu'il ne veut le laisser croire de rénovation dramatique, quoiqu'il joue aux côtés de Mlle Mars le Cid d'Andalousie de Lebrun. Il interprète encore quelques grands rôles sous la houlette de Taylor, mais ce sont désormais ses Souvenirs qui assurent la permanence de ses idées sur la condition d'acteur tandis que s'engage une terrible querelle de succession familiale, qui fort heureusement n'aura pas de véritable impact sur la fortune littéraire de ce grand tragédien. 